\title{
Global environmental health and sustainable development: the role at $\mathrm{Rio}+20$
}

\author{
Saúde ambiental global e desenvolvimento sustentável: \\ o papel na Rio +20
}

Gregg Lawrence Furie ${ }^{1}$ John Balbus ${ }^{2}$
${ }^{1}$ Robert Wood Johnson

Foundation Clinical

Scholars Program, Yale

School of Medicine. 333

Cedar Street SHM IE-61

PO Box 208088. 06520

New Haven CT USA.

john.balbus@nih.gov

${ }^{2}$ National Institute of

Environmental Health

Sciences

\begin{abstract}
The Rio+20 United Nations Conference on Sustainable Development represents a crucial opportunity to place environmental health at the forefront of the sustainable development agenda. Billions of people living in low-and middleincome countries continue to be afflicted by preventable diseases due to modifiable environmental exposures, causing needless suffering and perpetuating a cycle of poverty. Current processes of economic development, while alleviating many social and health problems, are increasingly linked to environmental health threats, ranging from air pollution and physical inactivity to global climate change. Sustainable development practices attempt to reduce environmental impacts and should, in theory, reduce adverse environmental health consequences compared to traditional development. Yet these efforts could also result in unintended harm and impaired economic development if the new "Green Economy" is not carefully assessed for adverse environmental and occupational health impacts. The environmental health community has an essential role to play in underscoring these relationships as international leaders gather to craft sustainable development policies.
\end{abstract}

Keywords Sustainable development, Environmental health, Global health, Climate change, Rio+20
Resumo A Conferência da ONU Rio +20 sobre desenvolvimento sustentável representa uma oportunidade crucial para colocar a saúde ambiental à frente da agenda de desenvolvimento sustentável. Bilhões de pessoas que vivem em países de baixa e média renda continuarão a ser afligidas por doenças evitáveis devido a exposições ambientais modificáveis causando sofrimento desnecessário e perpetuando um ciclo de pobreza. Processos de desenvolvimento econômico atuais, enquanto aliviam muitos problemas de saúde e sociais, estão cada vez mais ligados a ameaças de saúde ambiental, abrangendo desde poluição do ar e inatividade física até mudanças climáticas globais. Práticas de desenvolvimento sustentável tentam reduzir o impacto ambiental e deveriam, em teoria, reduzir as consequências adversas da saúde ambiental em relação ao desenvolvimento tradicional. Ainda assim, esses esforços podem também resultar em danos não intencionais e em pior desenvolvimento econômico se a nova "Economia Verde" não for cuidadosamente avaliada para impactos na saúde ambiental e ocupacional adversos. A comunidade da saúde ambiental tem um papel essencial para desempenhar, enfatizando estas relações enquanto líderes internacionais se reúnem para criar politicas de desenvolvimento sustentável.

Palavras-chave Desenvolvimento sustentável, Saúde ambiental, Saúde global, Mudança climática, Rio +20 


\section{Introduction}

The Rio+20 United Nations Conference on Sustainable Development represents a timely opportunity to identify key linkages between environmental health and sustainable development objectives. In principle, sustainable development - frequently defined as "development that meets the needs of the present without compromising the ability of future generations to meet their own needs"1 holds promise as a model by which to alleviate global poverty while avoiding the unintended adverse economic, social, and environmental consequences that have accompanied traditional models of economic development. Accomplishing this lofty and complex goal will require collaborations across sectors and disciplines, including crucial input from the environmental health community.

Health is both a precondition for and product of economic development ${ }^{2}$. Poor health- often a consequence of environmental exposurestraps populations in poverty, and therefore must be addressed to achieve development goals. A number of frameworks employed to help understand interactions between health and other economic sectors can illustrate an intersectoral approach to alleviating environmental health problems. The DPSIR (Driver-Pressure-State-ImpactResponse) model (see Figure 1) is particularly useful in describing how economic development policies and practices can ultimately impact human health by influencing landscapes and envi-

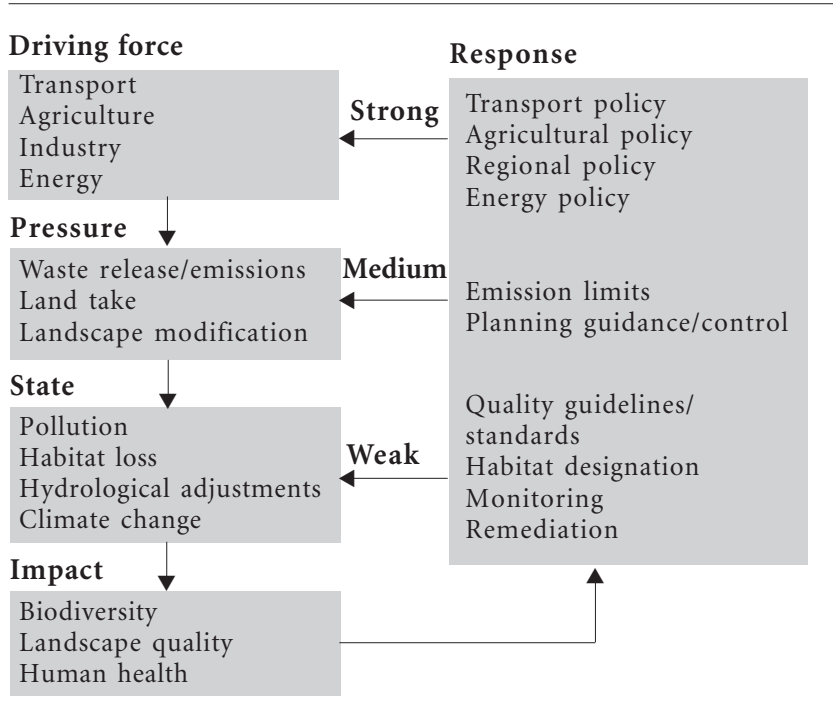

Figure 1. DPSIR Framework. Source: EU Integrated Environmental Health Impact Assessment System. http:// www.integrated-assessment.eu/ ronmental exposures. Avoiding the unintended consequences of development on the environment and health is essential to achieving sustainability objectives.

The environmental health community can make three key contributions to achieving sustainable development objectives: 1) supporting efforts to reduce modifiable environmental exposures that continue to perpetuate poverty in lowand middle-income countries (LMICs); 2) characterizing the environmental impacts of existing industries, technologies, and land-use patterns that are harmful to human health and 3) foreseeing potential unintended health effects of "green" technologies, industries, and occupations that will evolve out of efforts to promote sustainability.

\section{Environmental Health Affects Economic Development}

Many environmental exposures contribute to poor population health, which in turn constrains economic growth. Lost productivity due to premature death, chronic disability, or limited educational attainment compromises the economic well being of individuals while financial losses due to an unhealthy labor force strain entire industries $^{2}$. In addition, high childhood mortality rates - a common consequence of communicable diseases associated with poor environmental quality - may result in higher birth rates and larger family sizes. Sharing finite resources amongst more individuals can trap families in a cycle of poverty ${ }^{3}$. Environmentally mediated diseases often take their greatest toll among the most vulnerable populations, thus impeding economic growth where it is most needed.

It is estimated that $24 \%$ of the total global burden of disease - measured in disability-adjusted life years (DALYs) - can be attributed to modifiable environmental risk factors ${ }^{4}, 90 \%$ of which occurs in the developing world. Moreover, within LMICs, young populations are disproportionately affected ${ }^{4}$, robbing societies of those individuals with greatest potential for productivity and compounding other challenges to poverty reduction. Among those under the age of $15,34 \%$ of the total burden of disease can be attributed to the environment as compared to $17 \%$ among those aged 15 or older ${ }^{4}$. Lower respiratory tract infections, diarrheal illnesses, malaria, childhood cluster conditions, neglected tropical infections, and undernutrition are largely responsible for this difference. While communicable diseases closely associated with poverty represent a large fraction of the overall environ- 
mental burden, non-communicable diseases (NCDs) and unintentional injuries, which also disproportionately affect younger populations in LMICs, make important contributions as well.

\section{Communicable Diseases}

Lower respiratory infections and diarrheal illnesses, by far the leading contributors to environmentally mediated disease burden and mortality, represent two of the top five overall causes of death globally ${ }^{5}$. In the developing world, $41 \%$ of lower respiratory tract infections are due to indoor air pollution from burning biomass as a household energy source and $94 \%$ of diarrheal illnesses result from inadequate access to sanitation and uncontaminated water ${ }^{4}$.

Providing universal access to clean water and sanitation within LMICs could, through reduced incidence of diarrheal disease alone, yield estimated annual savings of US $\$ 1.7$ billion in reduced health care costs, US\$203 million from avoided non-medical household expenditures (e.g. transportation to healthcare facilities), US $\$ 3.5$ billion from avoided lost days of work and school, and US\$7.3 billion from prevented premature mortality ${ }^{6}$. An additional benefit would be the recovered economic value of convenience time (i.e. time no longer devoted to hauling water or traveling to sanitation facilities), estimated at US\$158 billion annually.

Malaria, the fourth leading cause of DALYs attributable to the environment- nearly all of which occurs in the developing world-, can also serve as an impediment to economic growth. Gallup and Sachs found that, all else being equal, countries with a high burden of malaria grew $1.3 \%$ less per person annually than those without malaria, and that reducing the burden of malaria by $10 \%$ was associated with a $0.3 \%$ greater rate of economic growth ${ }^{7}$.

\section{Noncommunicable Diseases}

Noncommunicable diseases, many of which have linkages to the environment, are the leading cause of mortality worldwide and their contribution to total mortality is rising in the face of shifting disease risk factors ${ }^{8}$. They account for nearly $45 \%$ of the overall disease burden in LMICs, with cardiovascular disease, chronic respiratory disease, cancer, neuropsychiatric disease, and diabetes making significant contributions ${ }^{5}$. Exposure to indoor and outdoor air pollution, chemicals, dust, heavy metals, and infectious agents represent important environmental risk factors. The built environment has been implicated more recently as a determinant of NCDs, mediated largely through its effects on physical activity ${ }^{9}$.
The high and rising prevalence of non-communicable diseases in LMICs threatens economic growth. In the absence of efforts to slow this trajectory in LMICs, diabetes, cardiovascular disease, chronic respiratory disease, and cancer are projected to result in US\$500 billion in annual economic losses between 2011 and 2025, equivalent to $4 \%$ of their combined GDP in $2010^{10}$. One study found that a $10 \%$ increase in mortality due to NCDs was associated with a $0.5 \%$ decrease in economic growth ${ }^{11}$. Environmental hazards contribute to this economic burden. A 2007 study by the World Bank found that the health impacts of urban air pollution in China resulted in economic losses equivalent to up to $3.7 \%$ of China's GDP, three-quarters of which was attributed to lost productivity due to premature mortality ${ }^{12}$.

Like communicable diseases, the burden of NCDs is borne disproportionately by younger populations in low- and middle-income countries, where $29 \%$ of deaths due to NCDs occur before the age of 60 , as compared to $13 \%$ in high-income countries $^{8}$. Vulnerable populations that are most susceptible to death or disability from NCDs due to limited access to preventive care or treatment are the least equipped to cope with resultant losses in productivity $^{8}$. Treatment of chronic diseases requires significant ongoing expenditures - a cost born primarily by individuals LMICs - that eat away at income or force individuals to forego therapy. LMICs, whose healthcare delivery systems are already strained and underfunded, may experience even greater financial challenges in the face of rising prevalence of NCDs.

\section{Unintentional Injuries}

Environmental factors are responsible for a greater proportion of disease burden due to unintentional injuries in the developing world ${ }^{4}$. Unintentional injuries- including the leading cause, road traffic injuries- result in three times as many DALYs per 100,000 population in the LMICs as compared to high-income countries ${ }^{13}$. Furthermore, road traffic accidents, occupational injuries, falls, and unintentional poisonings disproportionately affect younger age groups, contributing to premature mortality and disability. The annual economic cost of road traffic injuries in LMICs has been estimated at US\$65 billion.

\section{Economic Development Affects Environmental Health}

Economic development has undoubtedly been accompanied by dramatic improvements in human health but, paradoxically, has been accompa- 
nied by new environmental threats that can undermine these gains. Access to clean water, sanitation, improved sources of household energy, perinatal care, vaccinations, and adequate nutrition have virtually eliminated the traditional scourges of environmental health in high-income countries. Complex healthcare delivery systems and advances in medical therapies and technologies have compounded the impact of these achievements.

Yet the very process of economic development (enabled in part, as discussed, by improvements in population health) has also resulted in unintended adverse environmental health effects mediated largely by environmental contamination, exploitation of natural resources, and poorly informed land-use decisions. Population growth, rapid industrialization - often in countries with limited capacity or incentives to regulate environmental impacts -, adoption of western lifestyles and patterns of consumption, and globalization amplify these effects. Even as new environmental health threats are emerging, vulnerable populations continue to bear a disproportionate, historical burden of environmentally mediated diseases.

\section{Industrialization, Pollution, and Climate Change}

Industrialization has been a key driver of economic growth worldwide. Increased capacity for natural resource extraction, manufacturing, industrial agriculture, and global distribution- fueled by the very wealth it creates- often comes at the expense of the environment. The resultant pollution of air, land, and water has important implications for human health through increased risk of toxic exposures and compromised lifesustaining ecosystem services. Compounding these effects is an increasing demand for energy used to sustain further industrial expansion and support the increasingly energy-intensive lifestyles of a growing population.

Increasing demand for energy, met primarily through combustion of fossil fuels, is perhaps the greatest environmental health threat associated with economic development. Generation of electricity from coal and the use of petroleum products for transportation, industrial, and residential and commercial applications are leading causes of air pollution. Products of combustion, including particulate matter, nitrogen oxides, and ground level ozone, are major contributors to mortality and morbidity from cardiovascular and respiratory diseases. Outdoor air pollution is responsible for 1.3 million deaths annually, with the greatest burden in middle-income countries ${ }^{14}$. Global climate change, due in part to fossil fuel combustion, represents another significant and inequitable threat to public health ${ }^{15,16}$.

Changes in the natural environment due to anthropogenic climate change present numerous threats to human health. Extreme heat, more intense and frequent weather events, and exacerbation of the effects of air pollution have direct impacts on human health. Changing distributions of vector- and water-borne diseases, forced migration due to sea level rise or desertification, and disruption of vital ecosystem services result in indirect health effects.

Although uncertainties exist, it is estimated that in the year 2000, an excess of 160,000 deaths and over 5 million DALYs occurred as a consequence of climatic change that had occurred over the preceding 30 years ${ }^{17}$. The greatest burden was experienced in the developing world and disproportionately among children.

\section{The Changing Nature}

of Environmental Health Threats

Economic development has changed the characteristics of environmental health hazards, resulting in more indirect, global, and delayed health effects. Traditionally, the environmental health effects of industrial processes have been mediated through direct physiological impacts (e.g. exposure to air pollution resulting in cardiac or respiratory disease). Increasingly, the chain of causality from initial environmental insult to human health effects is growing longer (e.g. impacts from greenhouse gas emissions ultimately manifesting as mental health disorders in the setting of forced population migration or the built environment influencing behaviors, such as physical inactivity, that have associated health consequences). Economic development - characterized by industrialization, technology adoption, and globalization - is also changing the spatial and temporal scales over which environmental determinants affect human health.

As a consequence of global trade, individuals geographically isolated from a product's end user often experience the most harmful environmental exposures during that product's lifecycle (e.g. processes of manufacturing and disposal). The export of waste electronic and electronic equipment to developing countries- where informal repair and recycling and unregulated disposal result in toxic heavy metal and chemical exposures- serves as a useful example ${ }^{18}$.

Indirect environmental health effects also tend to exert their influence over larger spatial scales. Changes in weather patterns in the context of rising greenhouse gas emissions occur at a global scale, even though individuals experience the effects lo- 
The environmental health community's input is essential to the success of a movement towards sustainable development. Continued effort is necessary to eradicate traditional and modern environmental health threats that perpetuate the cycle of poverty in the developing world. These efforts will be bolstered by strategies to promote economic growth in low- and middle- income countries. But, as economic growth is achieved, new models of development that minimize unhealthy environmental externalities are needed. Vigilance will be necessary to ensure that these alternative technological models of development do not, themselves, have unanticipated adverse environmental health effects.

Promoting policies, technologies, and industries that have mutual benefits for human health and the environment- often termed co-benefitsmay be an effective way to align environmental health and sustainable development goals. Such strategies may appeal to policy makers given the potential for positive impacts in multiple sectors from single interventions. Emphasizing the environmental health benefits of sustainable development efforts may increase public acceptance and political buy-in. Preventing disease related to modifiable or avoidable environmental exposures lends a powerful economic argument for sustainable development interventions with health co-benefits.

Numerous strategies to achieve health co-benefits have been proposed, particularly within the context of reducing greenhouse gas emissions ${ }^{19}$. Promoting active transport - walking and cycling for transportation- through interventions at the level of the built environment and transportation policy could increase physical activity while reducing air pollution and greenhouse gas emissions from the transportation sector ${ }^{20}$. Increasing electricity generation from renewable energy sources would decrease both indoor and outdoor air pollution while reducing greenhouse gas production $^{21,22}$. Decreasing red meat consumption could have beneficial effects on cardiovascular disease while decreasing greenhouse gas production through reductions in conversion of forest to pasture land, methane gas release, and energy-intensive livestock feed production ${ }^{23}$. Sustainable agricultural systems could reduce expo-

sures to pesticides while reducing fossil fuel consumption, topsoil erosion, and fresh water depletion and pollution ${ }^{24}$. Adopting a "cradle-tocradle" philosophy of manufacturing- in which a product's component materials can be recycled indefinitely- could conserve natural resources while reducing the health effects of the material extraction and waste disposal processes ${ }^{25}$.

The Green Economy will serve as the economic engine of a movement towards sustainable development. By definition, the industries that make up the Green Economy will only be consistent with the principles of sustainable development if they do not have their own unintended environmental health effects. For example, the wind and solar energy industries will not be fully sustainable if associated occupational hazards are not mitigat$\mathrm{ed}^{26}$, regardless of their potential substantial positive impacts on health through reductions in air pollution and climate change. Buildings that achieve greater energy efficiency through tighter construction will not be achieving the goals of sustainable development if reductions in ventilation create greater exposure to indoor air pollution or mold. New technologies, yet undeveloped, will appear to hold great promise in helping meeting sustainable development objectives. Yet, even the most well intentioned efforts can have adverse environmental health effects, well demonstrated by the epidemic of arsenic poisoning in Bangladesh that resulted from wells tapped to provide access to uncontaminated sources of water ${ }^{27}$. Maintaining vigilance will be critical to ensuring that industries created to support sustainable development do not unintentionally cause ill-health, thereby resulting in further suffering for vulnerable populations and a burden on economic growth.

\section{Collaborations}

GL Furie and J Balbus participated equally in all stages of preparation of the article.

\section{Acknowledgements}

This article is the work product of an employee or group of employees of the National Institute of Environmental Health Sciences (NIEHS), National Institutes of Health (NIH), however, the statements, opinions or conclusions contained therein do not necessarily represent the statements, opinions or conclusions of NIEHS, NIH or the United States government. 
1. United Nations. Report of the World Commission on Environment and Development: Our Common Future. New York: United Nations; 1987.

2. Sachs J, Commission on Macroeconomics and Health. Macroeconomics and Health: Investing in Health for Economic Development. Geneva: World Health Organization; 2001.

3. Mirvis DM, Bloom DE. Population Health and Economic Development in the United States. JAMA 2008; 300(1):93-95.

4. Pruss-Üstun A, Corvalan C. Preventing Disease Through Healthy Environments: Towards an estimate of the environmental burden of disease. Geneva: World Health Organization; 2006.

5. Mathers C, Ma Fat D. The Global Burden of Disease: 2004 Update. World Health Organization; 2004.

6. Hutton G, Haller L, Bartram J. Economic and Health Effects of Increasing Coverage of Low Cost Household Drinking-Water Supply and Sanitation Interventions to Countries Off-Track to Meet MDG Target 10. Geneva: World Health Organization; 2007.

7. Gallup JL, Sachs JD. The economic burden of malaria. Am. J. Trop. Med. Hyg. 2001; 64(1-2 Suppl):8596.

8. Alwan A. Global Status Report on Noncommunicable Diseases 2010. Geneva: World Health Organization; 2010.

9. Sallis JF, Floyd MF, Rodríguez DA, Saelens BE. Role of Built Environments in Physical Activity, Obesity, and Cardiovascular Disease. Circulation 2012; 125(5): 729-737.

10. World Economic Forum, World Health Organization. From Burden to" Best Buys": Reducing the Economic Impact of Non-Communicable Disease in Low-and Middle-Income Countries. Geneva: World Economic Forum, World Health Organization; 2011.

11. Stuckler D. Population Causes and Consequences of Leading Chronic Diseases: A Comparative Analysis of Prevailing Explanations. Milbank Quarterly. 2008; 86(2):273-326.

12. The World Bank. Cost of Pollution in China: Economic Estimates of Physical Damages. Washington, DC: The World Bank; 2007.

13. Chandran A, Hyder AA, Peek-Asa C. The Global Burden of Unintentional Injuries and an Agenda for Progress. Epidemiol Rev. 2010; 32(1):110-120.

14. World Health Organization. Air Quality and Health. WHO. [accessed 2012 April 14]. Available at: http:// www.who.int/mediacentre/factsheets/fs313/en/index. html

15. Patz JA, Gibbs HK, Foley JA, Rogers JV, Smith KR. Climate Change and Global Health: Quantifying a Growing Ethical Crisis. EcoHealth. 2007; 4(4):397405.

16. Haines A, Kovats R, Campbell-Lendrum D, Corvalan C. Climate change and human health: impacts, vulnerability, and mitigation. The Lancet 2006; 367(9528):2101-2109.
17. McMichael AJ, Campbell-Lendrum D, Kovats S, Edwards S, Wilkinson P, Wilson T, Nicholls R, Hales S, Tanser F, Suer DL, Schlesinger M, Andronova N. Global Climate Change. In: Comparative Quantification of Health Risks: Global and Regional Burden of Disease due to Selected Major Risk Factors. Geneva: World Health Organization; 2004. p. 1543-1649.

18. Tsydenova O, Bengtsson M. Chemical hazards associated with treatment of waste electrical and electronic equipment. Waste Management. 2011; 31(1):45-58.

19. Haines A, McMichael AJ, Smith KR, Roberts I, Woodcock J, Markandya A, Armstrong BG, Campbell-Lendrum D, Dangour AD, Davies M, Bruce N, Tonne C, Barrett M, Wilkinson P. Public health benefits of strategies to reduce greenhouse-gas emissions: overview and implications for policy makers. Lancet 2009; 374(9707):2104-2114.

20. Woodcock J, Edwards P, Tonne C, Armstrong BG, Ashiru O, Banister D, Beevers S, Chalabi Z, Chowdhury Z, Cohen A, Franco OH, Haines A, Hickman R, Lindsay G, Mittal I, Mohan D, Tiwari G, Woodward A, Roberts I. Public health benefits of strategies to reduce greenhouse-gas emissions: urban land transport. Lancet 2009; 374(9705):1930-1943.

21. Wilkinson P, Smith KR, Davies M, Adair H, Armstrong BG, Barrett M, Bruce N, Haines A, Hamilton I, Oreszczyn T, Ridley I, Tonne C, Chalabi Z. Public health benefits of strategies to reduce greenhouse-gas emissions: household energy. Lancet 2009; 374(9705):1917-1929.

22. Markandya A, Armstrong BG, Hales S, Chiabai A, Criqui P, Mima S, Tonne C, Wilkinson P. Public health benefits of strategies to reduce greenhousegas emissions: low-carbon electricity generation. Lancet 2009; 374(9706):2006-2015.

23. Friel S, Dangour AD, Garnett T, Lock K, Chalabi Z, Roberts I, Butler A, Butler CD, Waage J, McMichael AJ, Haines A. Public health benefits of strategies to reduce greenhouse-gas emissions: food and agriculture. Lancet 2009; 374(9706):2016-2025.

24. Horrigan L, Lawrence RS, Walker P. How sustainable agriculture can address the environmental and human health harms of industrial agriculture. Environ Health Perspect. 2002; 110(5):445-456.

25. McDonough W, Braungart M, Anastas PT, Zimmerman JB. Applying the principles of green engineering to Cradle-to-Cradle design. Environ. Sci. Technol. 2003; 37(23):434A-441A.

26. Schulte PA, Chun H. Climate change and occupational safety and health: establishing a preliminary framework. J Occup Environ Hyg 2009; 6(9):542-554.

27. McLellan F. Arsenic contamination affects millions in Bangladesh. Lancet 2002; 359(9312):1127.

Artigo apresentado em 16/04/2012

Versão final aprovada em 26/04/2012 